\title{
SINKRONISASI EKONOMI PANCASILA DAN EKONOMI ISLAM
}

\author{
Muhammad Ali Akbar \& Moh. Idil Ghufron \\ Universitas Nurul Jadid
}

\begin{abstract}
This study discusses the concept of Pancasila economics and Islamic economics which have basic and not conflicting similarities. Both of these economic concepts share the goal of realizing social justice for all Indonesian people and social equality in prosperity and prosperity as stated in the five precepts of the Pancasila, as well as imbued with the first principle of the One Godhead Pancasila as its basis.

In this study also explained that between the Pancasila economic concepts and Islamic economics are two economic concepts whose basic principles, characteristics and systems are in accordance with the teachings in the Qur'an which is the holy book of Muslims. So that this can strengthen the confidence of the Indonesian people to not hesitate to implement the Pancasila economy which is the noble heritage of the founding fathers of the nation.

The method used in this study is library research, which refers to primal materials from two components which are the subject of discussion, namely the study of Pancasila economics and Islamic economics. And added with other books relating to the problems studied. While the writing method used is descriptive analytical, namely by collecting actual information in detail and thoroughly from the data obtained, to then describe the exact problem under study, then analyze it directly to be compiled as needed in this study by using data content analysis analysis.
\end{abstract}

Kata Kunci: Ekonomi, Pancasila, Islam, Al-Qur'an, Keadilan, Kesejahteraan. 


\section{A. PENDAHULUAN}

Indonesia merupakan negara yang tidak bisa lepas dari tatanan Kolonialisme dan Imprealisme. Selama 350 tahun Belanda mengusai Nusantara kemudian digantikan oleh Jepang dalam jangka waktu 3,5 tahun. Tidak heran jika pertarungan Fasisme (Trotsky) dan Komunisme (Stalin) terus membayangi perkembangan bangsa Indonesia. ${ }^{1}$

Pada tanggal 17 Agustus 1945 Indonesia secara politik bebas dari penjajahan. Di sinilah awal dari terbentuknya semua dimensi sebuah Negara, salah satunya adalah aspek ekonomi. Kedaulatan rakyat tidak hanya dicapai dengan demokrasi politik, namun juga harus dilalui dengan demokrasi ekonomi. Meskipun perekonomian Indonesia saat itu masih dipengaruhi oleh paham yang ditularkan para penjajah, namun semangat gotong royong yang merupakan jati diri sesungguhnya dari rakyat Indonesia telah mampu membentuk citranya sendiri. Semangat tersebut merupakan identitas dari ciri khas perekonomian bangsa Indonesia.

Ekonomi Indonesia harus berdasar usaha bersama. Dalam artian tidak membunuh pengusaha kecil serta tidak mengganggu aktifitas umum. Desentralisasi ekonomi yang dilakukan dengan memakai nama koperasi sebagai dasar perekonomian Indonesia, hingga negeri ini seperti sebuah taman yang berisi pohon-pohon koperasi yang buahnya dinikmati oleh seluruh rakyat.

Pancasila merupakan ideologi dan falsafah negara. Istilah tersebut terdapat dalam UUD 1945. Di sana disebutkan bahwa Pancasila adalah pedoman untuk meraih kebahagiaan, mencapai sejahtera dan perdamaian, serta kemerdekaan bagi sebuah negara berdaulat. ${ }^{2}$

Demekianlah hubung antara Islam dan Pancasila tercermin. Sila pertama tentang Ketuhanan sejalan dengan ajaran Islam, berkeyakinan bahwa Tuhan adalah Ahad. Kebijakan-kebijakan ekonomi yang mendasari tatanan perekonomian Indonesia tidak hanya bertumpu pada para ekonom semata, tetapi juga berdasarkan pertimbangan sosial kultural masyarakat serta aturan-aturan beragama. Melihat komposisi masyarakat Indonesia yang mayoritas Islam dengan acuan hukum dan kaidah serta pedoman mereka bertindak selalu berpijak pada aturan dan hukum Islam, maka secara logis dapat dilihat bahwa masyarakatpun akan melihat kebijakan-kebijakan ekonomi berdasarkan perspektif Islam. Demikinalah, sehingga ekonomi pancasila yang yang selama ini telah diterapkan oleh masyarakat Indonesia akan lebih bijak bila ditinjau dari sudut pandang Islam.

Beberapa kajian pustaka yang bisa menjadi rujukan dalam penelitian ini salah satunya adalah skripsi yang ditulis oleh Fitra Wardika sebagai

${ }^{1}$ Muhammad Hatta, Politik Kebangsaan dan ekonomi, (Jakarta: PT. KOMPAS Media Nusantara, 2015), 249

${ }^{2}$ Sulastomo, Cita-cita Negara Pancasila, (Jakarta: PT. KOMPAS Media Nusantara, 2015), 26-28. 
syarat mendapatkan gelar strata satu Fakultas Syari'ah dan IImu Hukum Universitas Islam Negeri Sultan Syarif Kasim pada tahun 2010, dengan judul skripsi "KONSEP PROF. DR. MUBYARTO TENTANG EKONOMI PANCASILA MENURUT PERSPEKTIF EKONOMI ISLAM".

Dalam penelitian tersebut penulis menemukan pokok pembahasan bahwa, sistem ekonomi yang dilandaskan pada nilai-nilai pancasila, merupakan usaha bersama yang berasaskan kekeluargaan dan kegotong-royongan. Bertujuan untuk mewujudkan keadilan sosial bagi seluruh rakyat Indonesia, kemerataan sosial dalam kemakmuran dan kesejahteraan sebagaimana yang tertuang pada sila kelima dalam pancasila yang merupakan tujuan akhir dari sistem ekonomi yang berlandaskan pada nila-nilai pancasila.

Penilitian ini bertujuan untuk memberikan penjelasan tentang konsep ekonomi pancasila. Sistem ekonomi pancasila merupakan sistem perekonomian yang memiliki kolerasi kuat dengan budaya asli yang berkembang di negara Indonesia dan tidak menyimpang dengan ajaran Islam. Pondasi utama dalam sistem tersebut adalah Ketuhanan Yang Maha Esa, Sehingga dapat dijadikan pedoman dalam menjalankan perekonomian Indonesia ke depan.

\section{B. METODE PENELITIAN}

Penelitian ini merupakan penelitian kepustakaan (library research), yaitu penelitian bahan-bahan yang bersumber dari berbagaimacam literature perpustakaan. Adapun teknik pengumpulan data dilakukan dengan studi kepustakaan, yakni berperan aktif mempelajari buku-buku yang berkaitan dengan pancasila dan ekonomi Islam.

Beberapa tahapan dalam mengaji data-data tersebut adalah:

1. Pengecekan Keabsahan Data

Pengecekan keabsahan data menerapkan empat kriteria, yaitu kepercayaan (cridebility), keteralihan (tranferability), kebergantungan (dependability), dan kepastian (konfirmability). ${ }^{3}$

2. Metode Penulisan

Dalam membahas dan menganalisa digunakan metode deskriptif analitik, yaitu mengumpulkan informasi aktual secara terperinci dari data sebagai deskipsi masalah untuk dianalisis secara langsung, sehingga dapat disusun sebagaimana yang diperlukan dalam penelitian ini.

3. Metode Analisa Data

Dengan menggunakan content analisis yang menganalisis pendapat seseorang kemudian ditambah pendapat lain lalu diambil kesimpulan. ${ }^{4}$

${ }^{3}$ Lexi J. Moleong, Metodologi penelitian kualitatif. cet. Ke-20, 327 


\section{c. HASIL PENELITIAN DAN PEMBAHASAN}

\section{a) Konsep Ekonomi Pancasila}

\section{Landasan Kultur dan Filosofis Pancasila}

Setiap bangsa di dunia memiliki satu pandangan hidup yang mempengaruhi, seperti komunisme yang banyak dipengaruhi oleh pola pikir Karl Marx. ${ }^{5}$ Berbeda dengan itu, Indonesia banyak dipengaruhi oleh kultur yang merupakan warisan leluhur, seperti kepercayaan terhadap Tuhan dan berkemanusiaan, nilai-nilai yang sudah lama menjadi kultur tersebut, kemudian oleh para pendiri bangsa dituangkan dalam bentuk pancasila. ${ }^{6}$

Oleh sebab itu dalam bernegara nilai-nilai pancasila banyak menjadi acuan, termasuk dalam aturan perundang-undangan, ekonomi, politik, hukum, sosial budaya, serta pertahanan dan keamanan. ${ }^{7}$

Memahami pancasila secara kronologis baik menyangkut rumusannya maupun peristilahannya memiliki pengertian sebagai berikut:

a. Pancasila Secara Etimologis

Istilah pancasila terdapat di perpustakaan Buddha, India yang bersumber dari kitab suci Tri Pitaka. Dalam kepercayaan Buddha, Pancasyiila yang memberikan lima aturan larangan bagi pemeluk agama tersebut, diantaranya:

1) Larangan embunuh.

2) Larangan mencuri.

3) Dilarang berhungan bebas, artinya dilarang zina.

4) Dilarang berkata palsu, artinya berdusta.

5) Dilarang minum-minuman yang menghilangkan pikiran. ${ }^{8}$

Sejalan dengan datangnya agama Hindu dan Buddha, maka ajaran pancasila Buddhismepun sampai ke perpustakaan Jawa. Istilah tersebut dapat ditemukan dalam keropak $^{9}$ Negarakertagama, kakawin $^{10}$ dalam pujangga istana Empu Prapanca. ${ }^{11}$ Terdapat dalam sarga 53 bait ke 2 :

${ }^{4}$ Bambang Suggono, Metodologi Penelitian Hukum, (Jakarta: Raja Grafindo Persada, 2006), 114-120.

${ }^{5}$ Kaelan, Pendidikan Pancasila, (Yogyakarta: Paradigma, 2014), 4.

${ }^{6}$ Kaelan, Pendidikan Pancasila, (Yogyakarta: Paradigma, 2014), 5.

${ }^{7}$ Ibid., 6.

${ }^{8}$ Ibid., 8.

${ }^{9}$ Daun lontar bertulis (naskah kuno di Jawa dan Bali).

${ }^{10}$ Sya'ir Pujian.

11 Kaelan, Pendidikan Pancasila, 13. 
"Yatnaggegwani pancasyiila kertasangkarbgisekaka karma" Berarti, Raja dengan setia melaksanakan lima pantangan (Pancasila) begitu pula upacara ibadat dan penobatan.

Bersamaan dengan runtuhnya kerjaan Majapahit, agama Islam mulai tersebar keseluruh Nusantara, walaupun masih terdapat sisa-sisa pengaruh ajaran Buddha yang dikenal oleh masyarakat Jawa dengan sebutan Pancasila.

b. Pancasila dalam Pandangan Historis

Pada tanggal 1 Juni 1945 berlangsung proses perumusan pancasila. Berawal dari sidang BPUKI pertama yang dipimpin oleh Radjiman Widyodiningrat. Dalam sidang tersebut membahas tentang rumusan yang menjadi dasar negara Indonesia, kemudian tampilah tiga orang pembicara: Yamin, Soepomo dan Soekarno. Soekarno menyampaikan usulan lima asas sebagai cikal-bakal dasar negara:

1) Nasionalisme atau kebangsaan Indonesia.

2) Internasionalisme atau Perikemanusiaan.

3) Mufakat atau Demokrasi.

4) Kesejahteraan Sosial.

5) Ketuhanan yang berkebudayaan. ${ }^{12}$

\section{Wacana Ekonomi Pancasila}

Dalam Pasal 33 UUD 1945, sangat jelas mencantumkan tujuan akhir kemakmuran rakyat secara maksimal. Perekonomian harus disusun berdasar demokrasi ekonomi, di mana kemakmuran masyarakat lebih diutamakan dari pada kemakmuran individu. ${ }^{13}$

Tujuan tersebut tentu sesuai dengan kelima pancasila. Secara financial ekonomi pancasila memang kurang menguntungkan, akan tetapi lebih manusiawi dari sistem ekonomi yang ada, sebab mendahulukan sosial, keadilan dan persaudaraan. ${ }^{14}$

Istilah ekonomi pancasila, sejak tahun 1980-an identik dengan tokoh Mubyarto. Mubyarto menegaskan bahwa, ekonomi pancasila harus terkait langsung dengan ekonomi masyarakat kecil dan bertumpu pada moralitas sosial, egalitarianisme, nasionalisme ekonomi, koperasi dan keseimbangan antara perencanaan pusat dan daerah. ${ }^{15}$

\footnotetext{
${ }^{12}$ Cindy Adam, Bung Karno Penyambung Lidah Rakyat Indonesia, (Jakarta: Gunung Agung, 1965), 237.

${ }^{13}$ Mubyarto, Ekonomi Pancasila, 126

${ }^{14}$ Tarli Nugroho, Polemik Ekonomi, 452.

${ }^{15}$ Abdurrahman Wahid, Islamku, Islam Anda, Islam Kita, (Jakarta: Projeck Demokrasi, 2011), 183.
} 


\section{b) Prinsip Dasar Ekonomi Pancasila}

Secara umum, landasan konstitusional ekonomi pancasila adalah pasal 33 UUD 1945. Pasal tersebut menyatakan:

1. Perekonomian disusun sebagai usaha bersama berdasar atas asas kekeluargaan.

2. Cabang-cabang produksi yang penting bagi negara dan yang menguasai hajat hidup orang banyak dikuasai oleh negara.

3. Bumi dan air kekayaan alam yang terkandung didalamnya dikuasai oleh negara dan dipergunakan sebesar-besarnya untuk kemakmuran rakyat. ${ }^{16}$

Dengan demikian, maka sebagai solusi dari masalah ekonomi yang dapat dilaksanakan adalah usaha yang ditangani oleh koperasi, swasta dan pemerintah. Sementara kelompok usaha yang sangat relefan dengan ayat 1 tersebut adalah koperasi dengan semangat kekeluargaan atau solidaritasnya. Inilah salah satu moralitas ekonomi pancasila yang terdapat dalam koperasi. ${ }^{17}$

\section{c) Sistem Ekonomi Pancasila}

Dalam penerapannya, ekonomi pancasila berlandaskan pada pancasila yang merupakan ideologi bangsa Indonesia. Pemerintah dan masyarakat memiliki kewajiban untuk berpihak kepada kepentingan ekonomi rakyat, dengan sistem yang demikian ekonomi pancasila dengan mudah dapat mewujudkan kemakmuran dan kesejahteraan.

Emil Salim yang merupakan salah satu pakar ekonomi pancasila menyatakan bahwa koperasi yang dikembangkan adalah bentuk dari realisasi ekonomi pancasila, namun fungsi koperasi itu sendiri harus sesuai dengan tujuan ekonomi pancasila. Oleh karena itu, hanya dalam sistem ekonomi pancasila inilah koperasi dapat tumbuh dan berkembang, penuh isi dan integritas. ${ }^{18}$

Ekonomi pancasila memiliki sistem sebagai berikut:

1. Ketuhanan Yang Maha Esa: artinya setiap warga negara digerakkan oleh rangsangan ekonomi, sosial dan moral.

2. Kemanusiaan yang adil dan beradab: ada tekad seluruh bangsa untuk mewujudkan kemerataan sosial.

3. Persatuan nasional: nasionalisme ekonomi.

4. Kerakyatan yang dipimpin oleh hikmat kebijaksanaan dalam permusywaratan/ perwakilan: demokrasi.

${ }^{16}$ Abdul Madjid dan Sri-Edi Swasono, Wawasan Ekonomi Pancasila, (Jakarta: UI Press, 1998), 33.

${ }^{17}$ Mohammad Hatta, Pelaksanaan Undang-Undang Dasar 1945 pasal 33, Kongres ISEI VIII, Juni 1979.

${ }^{18}$ Sri-Edi Swasono, Sistem Ekonomi dan Demokrasi Ekonomi, (Jakarta: UI Press, 1987), Cet. Ke-2, 122. 
5. Keadilan sosial bagi seluruh rakyat Indonesia: desentralisasi dan otonomi daerah. ${ }^{19}$

Tahun 1968-1978 adalah masa ekonomi mengalami perkembangan yang cukup besar. Krisis ekonomi dan landasan ekonomi perlu dipulihkan sebagai dukungan terhadap pertumbuhan selanjutnya. Oleh karena itu, Emil salim juga memberikan konsepsi tentang sitem ekonomi pancasila sebagai berikut:

1. Manusia pancasila harus menyeimbangkan antara kerja dengan doa sebagai makhluk yang berketuhanan, berprikemanusiaan, berkedaulatan rakyat, berkeadilan sosial dan berkebangsaan.

2. Ekonomi pancasila tidak mentolerir cara-cara produksi yang mengeksploitasi sesama manusia.

3. Sistem ekonomi yang memungkinkan pengembangan unsur kemanusiaan dan memperoleh akar yang kuat dalam hati sanubari masyarakat Indonesia.

4. Ekonomi pancasila berposisi sebagai netralisasi sistem ekonomi terpimpin dan ekonomi pasar.

5. Secara ideologis ekonomi pancasila berpaham demokrasi ekonomi dan berasaskan pada keseimbangan.

6. Menjadi kontrol arah perkembangan ekonomi sesuai target rencana.

\section{d) Konsep Ekonomi Islam}

\section{Prinsip-Prinsip Ekonomi Islam}

Secara umum, ekonomi islam adalah ekonomi yang berdasar pada lima nilai universal, yakni: ${ }^{20}$

a. Tauhid (Keesaan Tuhan)

Tauhid merupakan dasar dari ajaran Islam. Unsur dari paham tauhid adalah berkeyakinan bahwa "tiada sesuatu pun yang layak disembah selain Allah," dan "tidak ada pemilik langit, bumu dan isinya, selain dpipada Allah"

b. 'Adl (Keadilan)

Menurut Islam adil berarti "tidak menzalimi dan tidak dizalimi." Hubungan 'adl dan perekonomian adalah paham bahwa sebagai seorang pelaku ekonomi, semua orang tidak boleh bertujuan mencari keuntungan pribadi dengan cara merugikan hak orang lain dan atau merusak alam. ${ }^{21}$

c. Nubuwwah (Kenabian)

${ }^{19}$ Gunawan Sumodiningrat, Sistem Ekonomi, 59

${ }^{20}$ Adiwarman A. Karim, Ekonomi Mikro Islam, ( Jakarta: PT RAJAGRAFINDO PERSADA, 2016), 34

${ }^{21} \mathrm{Ibid}, 35$ 
Nabi adalah manusia yang diutus sebagai penyampai petunjuk dari Allah sebagai pedoman kehidupan manusia, adalah manusia yang menjadi teladan terbaik dalam kehidupan. Tidak hanya teladan dalam aspek hubungan dengan Allah sebagai hamba, namun juga aspek hubungan dengan manusia dan alam (Muamalah). Empat sifat Nabi yang harus diteladani adalah: Siddiq, Amanah, Fathanah, dan Tabligh.

d. Khilafah (Pemerintah)

Allah SWT berfirman dalam Al-Qur'an mengenai penciptaan manusia sebagai khalifah di muka bumi. Firman ini sesuai dengan nilai selanjutnya yang mendasari terhadap kehidupan manusia sebagai makhluk sosial yang tidak bisa dipisahkan dari interaksi (muamalah) sesama manusia, begitu pula dalam bidang ekonomi. ${ }^{22}$

e. Ma'ad (Hasil)

Secara bahsa ma'ad berarti kembali. Maksudnya adalah sebagai makhluk Allah SWT yang diberi kehidupan di muka bumi, pada masanya semua manusia akan kembali, hidup tidak hanya di dunia, namun akan berlanjut hingga alam akhirat. Sebab itulah dalam banyak firmnnya Allah SWT. mengingatkan manusia agat tidak terlalu cinta pada dunia.

Dalam artian lain, Ma'ad berarti juga imbalan/ganjaran. Nilai inilah dalam dunia ekonomi oleh Imam Al-Ghazali dijadikan dasar motivasi pelaku ekonomi untuk memperoleh laba. Sehingga dengan dasar demikianlah konsep profit diperbolehkan dalam islam. ${ }^{23}$

\section{Kararteristik Ekonomi Islam}

Menurut Yusuf Qardhawi Ekonomi Islam mempunyai empat karakteristik:.24

a. Rabbaniyyah (Ketuhanan)

Karakteristik pertama dalam ekonomi islam adalah rabbaniyyah. Maksudnya adalah setiap perilaku ekonomi haruslah berdasarkan pada prinsip ketaatan yang mendahulukan hukum Allah SWT. yaitu, melaksanakan segala perintahnya dan menjauhi segala larangannya.

b. Insaniyyah (Kemanusiaan)

\footnotetext{
${ }^{22} \mathrm{Ibid}, 40$
}

${ }^{23}$ Ibid, 41-42

${ }^{24}$ Yusuf Qardhawi, Peran Nilai dan Moral Dalam Perekonomian Islam, ter. Didin Hafidhuddin (Jakarta: Robbani Press, 1997), 135-358 
Unsur kemanusian tak luput menjadi salah satu karakteristik dari ekonomi islam. Sebagai peran dan tujuan dari kegiatan ekonomi itu sendiri tentu peran manusia menjadi salah satu yang harus diperhatikan dalam melaksanakan kegiatan ekonomi. Memahami bahwa tujuan akhir dari kegiatan ekonomi adalah untuk mencapai kehidupan yang baik di dunia dan akhirat.

c. Akhlaqiyyah (Etika)

Etika merupakan salah satu hal yang tidak bisa dipisahkan dalam aktifitas ekonomi, begitu juga dalam semua aktifitas yang berkaitan dengan sosial masyarakat.

d. Wasathiyyah (Keseimbangan)

Inilah salah satu tujuan penting yang harus dicapai dari perilaku ekonomi, yaitu keseimbangan dalam kehidupan bermasyarakat.

\section{e) Sinkronisasi Ekonomi Pancasila Dan Ekonomi Islam}

Hasil penelitian ini menunjukkan bahwa ekonomi Islam merupakan bentuk aktifitas perekonomian yang berdasarkan pada Al-Qur'an dan Al-Hadits, sementara ekonomi pancasila bersumber terhadap ideologi pancasila. Perekonomian dalam Islam adalah perekonomian yang berlandaskan kepada tauhid dengan segala komponennya seperti: keimanan, pengabdian, interaksi sesama manusia dengan alam. AlQur'an menjelaskan fungsi harta adalah sebagai pelantara bukan tujuan. Tujuan yang sesungguhnya adalah sebagai bentuk ibadah kepada Allah SWT. ${ }^{25}$

Dalam pembukaan UUD 1945, dijelaskan bahwa Indonesia adalah sebuah Negara yang mengakui Ketuhanan Yang Maha Esa, juga memiliki tujuan memperjuangkan kemanusiaan yang adil dan beradab. Ketuhanan dalam pancasila menegaskan etika bangsa untuk melaksanakan "kehidupan publik-politik berdasarkan nilai-nilai moralitas dan budi pekerti luhur yang tinggi. ${ }^{26}$ Secara khusus orientasi sila pertama pancasila merupakan asas yang mendasari pada empat sila selanjutanya.

Ekonomi pancasila merupakan sistem perekonomian yang dilandaskan terhadap nilai-nilai pancasila. Juga menjadikan UUD 1945 sebagai pijakan utama untuk menjalankan sistem perekonomian, seperti yang terdapat dalam pasal 33 UUD $1945 .^{27}$

${ }^{25}$ Buya Hamka, Keadilan Sosial., 75.

Yudi Latif, Negara Paripurna: Historis, Rasionalitas dan Aktualitas Pancasila, (Jakarta: PT. Gramedia Pustaka, 2015),

${ }^{27}$ Mawardi, Ekonomi Islam, (Pekanbaru: Alaf Riau, 2007), 133. 
Hal tersebut relevan dengan konsep tauhid yang menjadi pondasi utama dalam menjalankan perekonomian Islam. ${ }^{28}$

Kedua sumber antara ekonomi pancasila dan Islam dikuatkan dalam ayat suci Al-Qur'an Surah An-Nisa', ayat 1 Allah SWT berfirman:

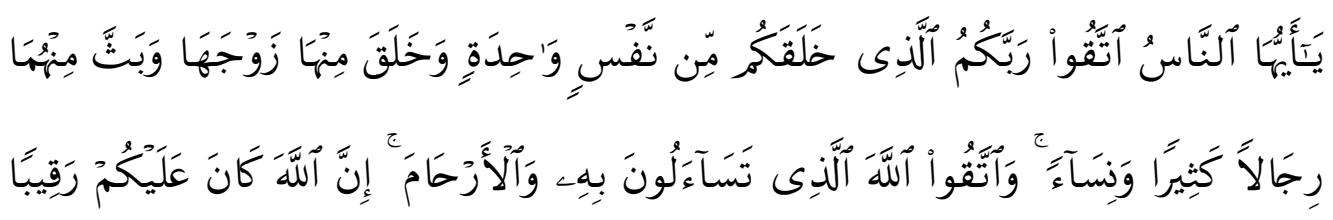

Artinya: "Hai sekalian manusia, bertakwalah kepada Tuhan-mu yang telah menciptakan kamu dari seorang diri, dan dari padanya, Allah menciptakan istrinya; dan dari pada keduanya Allah memperkembang biakkan laki-laki dan perempuan yang banyak. dan bertakwalah kepada Allah yang dengan (mempergunakan) nama-Nya kamu saling meminta satu sama lain, dan (peliharalah) hubungan silaturrahim. Sesungguhnya Allah selalu menjaga dan mengawasi kamu."29

Ayat tersebut menjelaskan bahwa menurut agama Islam, suatu bangsa adalah keluarga besar yang harus selalu bekerja sama dalam kehidupan berekonomi dan tidak dibenarkan terhadap persaingan yang saling mematikan.

Terdapat beberapa letak persamaan antara ekonomi Islam dengan ekonomi pancasila diantaranya adalah:

1. Kedua sistem ini memiliki kesamaan visi sosial dan moral, seperti yang dijelaskan dalam Al-Qur'an Surah An-Naml ayat 5, yaitu:

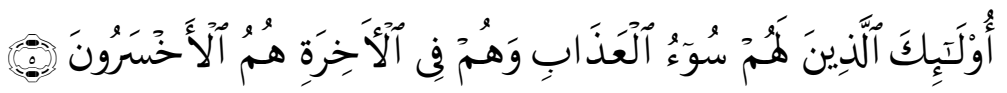

Artinya: "Mereka Itulah orang-orang yang mendapat (di dunia) azab yang buruk dan mereka di akhirat adalah orang-orang yang paling merugi. 30

2. Memiliki keinginan untuk mewujudkan keadilan dan pemerataan sosial, bahkan jaminan sosial, hal ini dijelaskan dalam Al-Qur'an surah An-Nahl ayat 90:

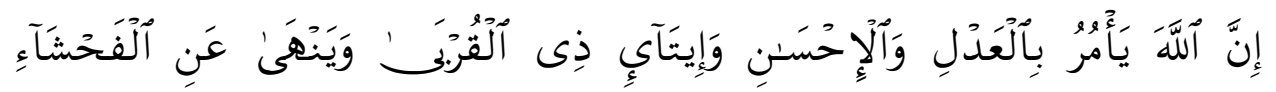

${ }^{28}$ Veithzal Rivai dkk, Islamic Business And Economic Ethic, (Jakarta: PT.Bumi Aksara, 2012), 53.

${ }^{29}$ Departemen Agama RI, Al-Qur'an, 517.

${ }^{30}$ Ibid., 378. 


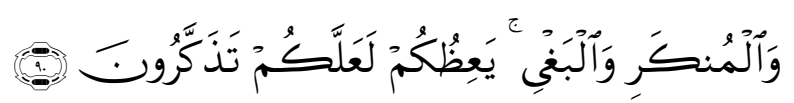

Artinya: "Sesungguhnya Allah menyuruh (kamu) berlaku adil dan berbuat kebajikan, memberi kepada kaum kerabat, dan Allah melarang dari perbuatan keji, kemungkaran dan permusuhan. Dia memberi pengajaran kepadamu agar kamu dapat mengambil pelajaran."31

3. Nasionalisme ekonomi, semangat kekeluargaan, saling mencintai dan tenggang rasa. Apabila telah merata terhadap elemen masyarakat, maka akan menjelma menjadi semangat solidaritas sosial menjadi kemerataan sosial. ${ }^{32}$

4. Kooperasi (Baitul mal wat tamwil) menjadi kekuatan dalam berekonomi. Harta dalam Islam adalah milik Allah, yang digunakan untuk kepentingan bersama. Islam tidak menghendaki perbedaan kemampuan dan kesanggupan menghilangkan maksud dari kerangka keadilan, sehingga didirikan baitul maal sebagai keperluan bersama dari semangat saling membantu untuk mencapai kesejahteraan kolektif. Tujuan dari didirikannya baitul maal ini sama persis dengan tujuan didirikannya koperasi.

5. Kesamaan dalam keseimbangan umtuk melaksanakan kebijakan ekonomi. Harta benda adalah kepunyaan bersama, akan tetapi, AlQur'an menegaskan bahwa harta benda adalah milik Allah. Manusia menjadi khalifah atau wakil Tuhan di muka bumi untuk memelihara untuk kepentingan berasama. ${ }^{33}$

Selain beberapa kesamaan prinsip di atas, pancasila yang merupakan dasar ekonomi pancasila sangat erat hubungannya dengan Al-Qur'an sebagai sumber dari ekonomi Islam, antara lain:

1. Pada sila pertama, "Ketuhanan Yang Maha Esa" mengajarkan pesan tauhid untuk selalu mengesakan Tuhan. Dalam ajaran akidah Islam yang harus tertanam di diri setiap muslim, seperti surat al-Baqarah ayat 163:

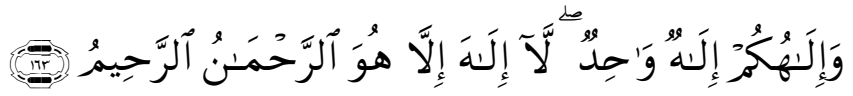

Artinya: "Dan Tuhanmu adalah Tuhan yang Maha Esa; tidak ada Tuhan melainkan Dia yang Maha Pemurah lagi Maha Penyayang. 34

\footnotetext{
${ }^{31}$ Departemen Agama RI, Al-Qur'an, 278.

${ }^{32}$ Yudi Latif, Neagara Paripurna, 462.

${ }^{33}$ Buya Hamka, Keadilan Sosial, 76.

${ }^{34}$ Departemen Agama RI, Al-Qur'an, 25.
} 
2. Sila kedua, "kemanusiaan yang adil dan beradab" merupakan spirit ajaran Islam untuk menjunjung tinggi nilai-nilai kemanusiaan dan melestarikan keadilan disegala dimensi kehidupan. Allah berfirman dalam Al-Qur'an Surat Al-Maidah ayat 8:
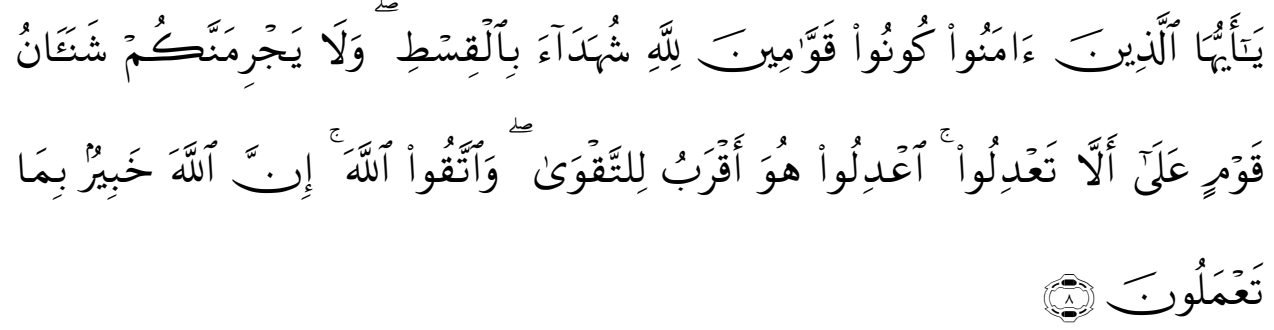

Artinya: "Hai orang-orang yang beriman hendaklah kamu jadi orang-orang yang selalu menegakkan (kebenaran) karena Allah, menjadi saksi dengan adil. dan janganlah sekali-kali kebencianmu terhadap sesuatu kaum, mendorong kamu untuk berlaku tidak adil. Berlaku adillah, karena adil itu lebih dekat kepada takwa. dan bertakwalah kepada Allah, Sesungguhnya Allah Maha mengetahui apa yang kamu kerjakan. 35

3. Sila ketiga, "persatuan Indonesia" yang menjadi cita-cita dari bangsa ini juga merupakan ajaran Islam yang memerintahkan untuk menjaga kestabilan persatuan dan kesatuan sesama manusia. Sebagaimana firman Allah dalam Al-Qur'an:

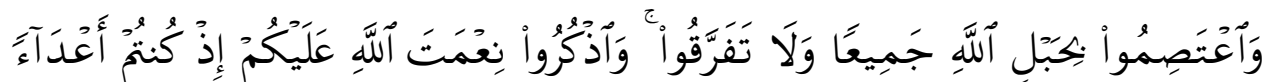

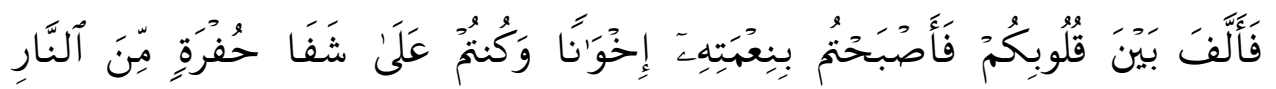

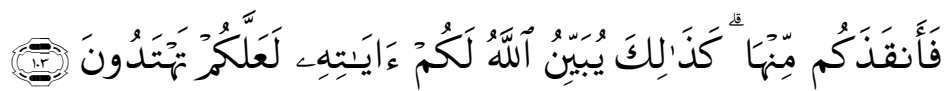

Artinya: "Dan berpeganglah kamu semuanya kepada tali (agama) Allah, dan janganlah kamu bercerai berai, dan ingatlah akan nikmat Allah kepadamu ketika kamu dahulu (masa Jahiliyah) bermusuh-musuhan, maka Allah mempersatukan hatimu, lalu menjadilah kamu karena nikmat Allah, orang-orang yang bersaudara; dan kamu telah berada di tepi jurang neraka, lalu Allah menyelamatkan kamu dari padanya. Demikianlah Allah menerangkan ayat-ayat-Nya kepadamu, agar kamu mendapat petunjuk."36 
4. Sila keempat, "kerakyatan yang dipimpin oleh hikmat kebijaksanaan dalam permusyawaratan perwakilan" sejalan dengan ajaran Islam telah digariskan di dalam AI-Qur'an:

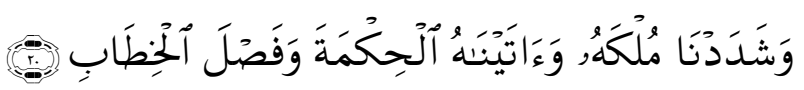

Artinya: "Dan kami kuatkan kerajaannya dan Kami berikan kepadanya hikmah dan kebijaksanaan dalam menyelesaikan perselisihan."37

5. Sila yang terkahir adalah "Keadilan sosial bagi seluruh rakyat Indonesia." Hal ini telah termaktub dalam Al-Qur'an surat An-Nahl ayat 90:

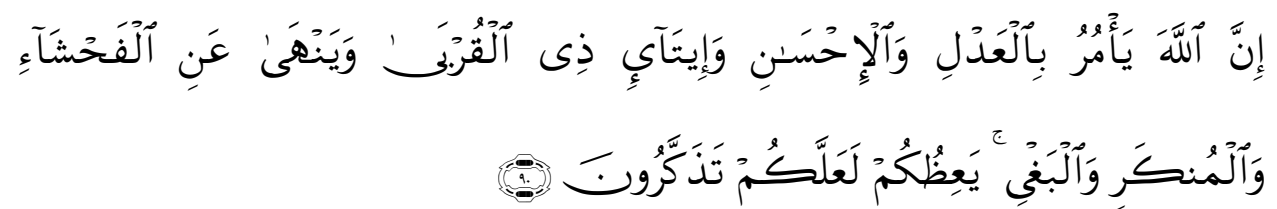

Artinya: "Sesungguhnya Allah menyuruh (kamu) Berlaku adil dan berbuat kebajikan, memberi kepada kaum kerabat, dan Allah melarang dari perbuatan keji, kemungkaran dan permusuhan. Dia memberi pengajaran kepadamu agar kamu dapat mengambil pelajaran."38

\section{KESIMPULAN DAN SARAN}

Berdasarkan pembahasan tentang esensi ekonomi pancasila dalam perspektif Islam, maka terdapat implikasi bahwa ekonomi pancasila merupakan perilaku ekonomi yang berpondasikan terhadap ideologi negara Indonesia yaitu pancasila. Ekonomi pancasila adalah usaha bersama yang berdasarkan gotong-royongan nasional dengan bertujuan untuk mewujudkan keadilan sosial dalam kemakmuran dan kesejahteraan bersama. Sebagaimana yang tertuang dalam sila kelima pancasila "keadilan sosial bagi seluruh rakyat Indonesia" menjadi tujuan utama dari terbentuknya sistem ekonomi pancasila. Dalam pandangan Islam, ekonomi pancasila merupakan sistem perekonomian yang sesuai dengan semangat Ekonomi Islam. Kedua sistem tersebut memiliki kesamaan tujuan untuk mewujudkan keadilan sosial dan kesejahteraan bersama, dengan menaruh perhatian terhadap kondisi sosial disekitarnya.

Berdasarkan kesimpulan yang telah dipaparkan, terdapat beberapa saran sebagai berikut : 
1. Diharapkan dengan hadirnya jurnal ini, seluruh insan akademis dapat lebih memahami konsep ekonomi Islam dan ekonomi pancasila, sehingga kemudian dapat memilih rujukan yang baik dalam menjalankan sistem perekonomian yang membawa dampak positif terhadap kehidupan sosial bermasyarakat, berbangsa dan bernegara.

2. Bagi para cendikiawan, hendaknya dapat meneliti lebih lanjut argumentasi ekonomi agar dapat dikembangkan sesuai dengan kebutuhan pasar.

3. Diharapkan kepada pihak pemerintah agar melaksanakan strategi pembangunan ekonomi yang sesuai dengan cita-cita dan kebutuhan masyarakat.

\section{DAFTAR PUSTAKA}

Adam, Cindy. 1965. Bung Karno Penyambung Lidah Rakyat Indonesia. Jakarta: Gunung Agung

Departemen Agama RI. 2010. Al-Qur'an dan Terjemahan. Bandung: Hilal Hamka. 2015. Keadilan Sosial dalam Islam. Jakarta: Gema Insani

Hatta, Muhammad. 2015. Politik Kebangsaan dan Ekonomi. Jakarta: PT. KOMPAS Media Nusantara

Kaelan. 2014. Pendidikan Pancasila. Yogyakarta: Paradigma

Latif, Yudi. 2015. Negara Paripurna: Historis, Rasionalitas dan Aktualitas Pancasila. Jakarta: PT. Gramedia Pustaka

Madjid, Abdul, dan Sri-Edi Swasono. 1998. Wawasan Ekonomi Pancasila. Jakarta: UI Press

Mawardi. 2007. Ekonomi Islam. Pekanbaru: Alaf Riau

Mubyarto. 1987. Ekonomi Pancasila, 126 Gagasan dan Kemungkinan. Jakarta: LP3ES

Nitisastro, Widjojo, dkk. 1965. Masalah-Masalah Ekonomi dan Faktorfaktor IPOLOS (Ideologi, Politik, Sosial). Jakarta: LEKNAS

Nugroho, Tarli. 2016. Polemik Ekonomi Pancasila: Pemikiran dan Catatan, 1965-1985. Yogyakarta: Mubyarto Institute

Patria, Nezar., dan Andi Arief. 2015. Antonio Gramsci Negara dan Hegemoni. Yogyakarta: Pustaka Pelajar

Qardhawi, Yusuf. ter. Didin Hafidhuddin. 1997. Peran Nilai dan Moral Dalam Perekonomian Islam. Jakarta: Robbani Press

Rivai, Veithzal, dkk,. 2012. Islamic Business And Economic Ethic. Jakarta: PT.Bumi Aksara

Said, Muh. 2008. Pengantar Ekonomi Islam dasar-dasar dan penngembangan. Pekanbaru: Suska Press 
Muhammad Ali Akbar \& Moh. Idil Ghufron_Sinkronisasi Ekonomi Pancasila Dan Ekonomi Islam

Sulastomo. 2015. Cita-cita Negara Pancasila. Jakarta: PT. KOMPAS Media Nusantara

Sumodiningrat, Gunawan. 1999. Sistem Ekonomi Pancasila dalam Perspektif. Jakarta: Impac Wahana Cipta

Swasono, Sri-Edi. 1987. Sistem Ekonomi dan Demokrasi Ekonomi. Jakarta: UI Press

Wahid, Abdurrahman. 2011. Islamku, Islam Anda, Islam Kita. Jakarta: Projeck Demokrasi 